\title{
AN IMMEDIATE FIT AND ADJUSTABLE TRANSTIBIAL PROSTHETIC SYSTEM; A PROSPECTIVE FEASIBILITY AND EFFICACY STUDY
}

\author{
Timothy R. Dillingham ${ }^{1}$, Jessica Kenia ${ }^{1 *}$, Frances S. Shofer ${ }^{2}$, Jim Marschalek ${ }^{3}$
}

${ }^{1}$ Department of Physical Medicine and Rehabilitation, University of Pennsylvania School of Medicine; Philadelphia, PA, USA. ${ }^{2}$ Department of Emergency Medicine, University of Pennsylvania School of Medicine; Philadelphia, PA, USA.

${ }^{3}$ Advanced Design Concepts, Pewaukee, WI, USA.

* Email: Jessica.Kenia@uphs.upenn.edu

DOI: https://doi.org/10.33137/cpoj.v1i2.32025

\section{INTRODUCTION}

Limb loss rates globally are rising and there is a large unmet need for an affordable and accessible prosthetic system for this growing US and International population. The purpose of this prospective cohort study was to assess the feasibility and utility of a novel immediate fit modular prosthetic system (IFIT Prosthetics, LLC ${ }^{\text {TM }}$ prosthesis) for transtibial amputees.

\section{METHODS}

Transtibial amputees at least 6 months post amputation currently using a conventional prosthesis were enrolled after full consent under an IRB approved protocol. They were excluded if they had skin wounds, excessive limb or phantom pain, and a neurological disorder that interfered with gait. The PI fit and aligned all devices. The participants were instructed to wear the prosthesis for a two-week evaluation period in order to compare it to their own device. A questionnaire based off the Prosthetic Evaluation Questionnaire (PEQ) was given on their current device during their first visit and they evaluated the IFIT prosthesis during the follow up visit. A gait biomechanical analysis and pressure evaluations (Fujifilm Prescale $\AA$ ) were conducted. All adverse events or mechanical issues were recorded.

\section{RESULTS}

Twenty-six participants agreed to participate in the trial. Twenty-two amputees completed the study, with four not willing to travel for follow up. Mean age for subjects completing the study was $51.1, \mathrm{SD} \pm 11.3$ years, with 3 females and 19 males enrolled. Fourteen were dysvascular amputees and eight had traumatic etiologies. A significant difference in self-reported satisfaction was found for the IFIT device 29.33, SD \pm 4.51 versus mean score for own device $=25.52, \mathrm{SD} \pm 6.8(\mathrm{p}=0.0323)$ (Table 1). No falls or limb ischemia were reported. Two people had minor skin breakdown that resolved with realigning and altering socket liner. Gait biomechanics revealed no differences in any temporal values. Pressures were significantly lower in the iFIT prosthesis versus a conventional prosthesis $\mathrm{p}=.0014$ and at anterior tibia $\mathrm{p}=.0002$, and lateral side $\mathrm{p}=.013$ (Figure 1 ).

\begin{tabular}{|c|c|c|c|c|}
\hline Variable & iFIT & $\begin{array}{c}\text { Conventi } \\
\text { onal }\end{array}$ & \begin{tabular}{|c|} 
Differ \\
ence
\end{tabular} & P-value \\
\hline \multicolumn{5}{|l|}{ Self-reported outcomes } \\
\hline $\begin{array}{l}\text { Questionnaire (intention to } \\
\text { treat analysis that includes } \\
\text { dropouts modeled to be } \\
\text { worse off } \mathrm{N}=26 \text { ) }\end{array}$ & $29(4.5)$ & $\begin{array}{r}25.4 \\
(6.8)\end{array}$ & 3.6 & $0.032^{*}$ \\
\hline $\begin{array}{l}\text { Questionnaire (actual } \\
\text { completion group } \mathrm{N}=22 \text { ) }\end{array}$ & $\begin{array}{c}30.86 \\
(3.43)\end{array}$ & $\begin{array}{c}24.82 \\
(7.37)\end{array}$ & 6.04 & $.0023^{*}$ \\
\hline \multicolumn{5}{|l|}{$\begin{array}{l}\text { Biomechanical comparisons } \\
(\mathrm{N}=17)\end{array}$} \\
\hline Limp Index $x^{\star *}$ Prosthetic & 0.99 & 0.97 & 0.02 & NS \\
\hline Limp Index $x^{\star *}$ Sound & 1.01 & 1.03 & -0.02 & NS \\
\hline Stride Length Prosthetic & 1.22 & 1.22 & 0 & NS \\
\hline Stride Length Sound & 1.22 & 1.21 & 0.01 & NS \\
\hline Double Support Prosthetic & 0.37 & 0.36 & 0.01 & NS \\
\hline Double Support Sound & 0.37 & 0.35 & 0.02 & NS \\
\hline $\begin{array}{l}\text { Stance Phase \% (foot off) } \\
\text { Prosthetic }\end{array}$ & 64.3 & 63.4 & 0.89 & NS \\
\hline $\begin{array}{l}\text { Stance Phase \% (foot off) } \\
\text { Sound }\end{array}$ & 65.2 & 65.0 & 0.2 & NS \\
\hline Walking Speed Prosthetic & 0.98 & 0.98 & 0 & NS \\
\hline Walking Speed Own & 0.98 & 0.98 & 0 & NS \\
\hline
\end{tabular}

\section{DISCUSSION}

The IFIT prosthesis compared favorably to subjects' conventional prostheses in terms of self-reported satisfaction and gait. Intra-Socket pressures were lower than in conventional devices. The IFIT device demonstrated safety and efficacy in this prospective trial. 
With its potential cost and accessibility advantages, the IFIT prosthetic system holds promise to enhance access for transtibial amputees.

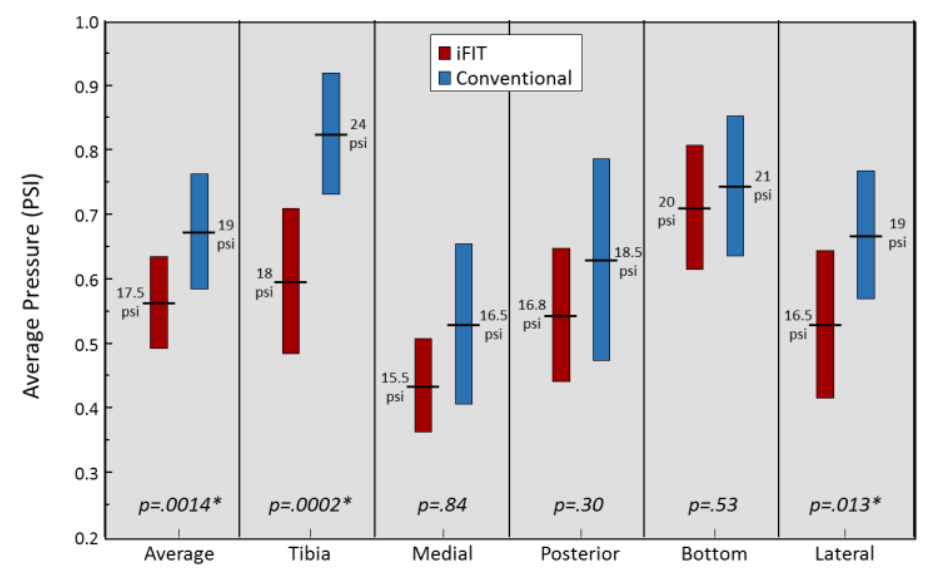

Figure 1. Average Peak Pressure: iFIT versus Conventional Prosthesis. An estimated pressure in pounds/square inch (psi) is indicated next to the mean values and reflects an estimated pressure as determined through nomographic scoring (Fujifilm ). These are peak pressures that occurred with ambulation.

\section{CONCLUSION}

The iFIT transtibial prosthetic system is safe and effective in this short term trial. A larger multicenter comparative effectiveness study is needed to confirm these findings.

\section{ACKNOWLEDGMENT}

This study was funded by the National Institutes of Health, National Institute on Aging (Grants: 2SB1AG050430-06 and 2R42AG050430-04) and the NICHD and NCMRR (Grants 2R42 HD 069067-02 and 1R41HD069067 - 01). Dr. Dillingham founded the company IFIT Prosthetics, LLC® and is the major owner and director. Patient testing occurred at the University of Pennsylvania under sub-contact and included a Provost conflict of interest management plan for the PI.

\section{DISCLAIMER AND CONFLICT OF INTEREST STATEMENT}

The PI founded the company IFIT Prosthetics, LLC and is the major owner and director. He has financial interest in the prosthetic system being presented in this article. He signed $\mathrm{NIH}$ compliant conflict of interest management agreements with the University where research was conducted. 